\title{
Kant: autonomia ou estética compromissada?
}

\author{
Michael Korfmann*
}

\begin{abstract}
This article analyses the influence of Kant on conceptions and definitions of modern literature and art in publications by Lyotard, Kothe, Weber and Luhmann. It is argued that central issues in these publications, such as artistic autonomy, the sublime and the concept of L'art pour l'art, are adopted directly from Kant's philosophical work and still serve as paradigms in the discussion of origin and status of modern social structure and its art production.
\end{abstract}

Keywords: Kant; Autonomy; Modern Art.

Zusammenfassung: Der Artikel beschäftigt sich mit dem Einfluss von Kant auf Konzepte der modernen Kunst, wie sie etwa in Arbeiten von Lyotard, Kothe, Weber oder Luhmann formuliert werden. Zentrale Punkte sind die Begriffe der Autonomie, des Erhabenen sowie L'art pour l'art als Paradigmen innerhalb der Diskussion über Beginn und Entwicklung der künstlerischen und sozialen Moderne.

Stichwörter: Kant; Autonomie; moderne Kunst.

Palavras-chave: Kant; autonomia; arte moderna.

\section{Introdução}

O olhar estético, e com isso filosófico, de Kant sobre as artes continua a servir como referência para diversas tentativas teóricas de descrever

O autor é Professor Adjunto no Instituto de Letras da UFRGS.

Endereço para correspondência: Prof. Michael Korfmann - UFRGS Instituto de Letras / Setor de Alemão, Avenida Bento Gonçalves, 9500. 91509-970 Porto Alegre, R.S.

Endereço eletrônico:michael.korfmann@ufrgs.br 
ou conceber a literatura e a arte dos últimos duzentos anos. $\mathrm{O}$ interesse constante em buscar na sua concepção estética paralelos a concepções mais recentes percebe-se, por exemplo, em Belo, Sublime e Kant (DUARTE: 1998), em que são destacados pontos de aproximação de Kant com Benjamin ou Bachelard, entre outros. As concepções resultantes desta investigação freqüentemente são contraditórias. Enquanto os defensores de uma modernidade artística proclamam Kant como fundador teórico da autonomia das artes, uma certa linha do chamado pós-modernismo busca nos seus textos, sobretudo no conceito do sublime, argumentos para justificar o inapresentável nas obras artísticas como elemento constitutivo destas. Evidentemente ainda há leituras de Kant nas quais a qualidade estética da arte é vista como inseparavelmente ligada ao ético.

Apresentamos um exemplo concreto destas leituras opostas: enquanto Jean-François Lyotard comenta, em relação a Kant, que "a separação entre estética e ética aparece aqui como irrevogável” (1989: 95), Flavio Kothe afirma que "Kant insistiu em uma estrutura de conexão entre o ético e o artístico, na qual ambos se afirmam como algo que se dispõe em um horizonte além de qualquer interesse pessoal ou grupal" (1999: 80).

Poderíamos supor aqui uma recepção adversa de Kant no lado europeu e brasileiro, mas não nos parece sustentável criar tal oposição. Ao invés de reduzir as discussões sobre o significado da obra kantiana a uma divisão social-geográfica, partimos da convicção que as posições adversas não resultam de um contexto político claramente identificável, mas, antes de tudo, da diversividade de posicionamentos teóricos que podem ser encontrados em nível universal.

Partimos neste trabalho de uma diferença básica estabelecida, por Kant, entre a arte e seu ambiente, especificamente as ciências em ascensão no seu tempo. Ele mesmo constata uma progressibilidade das ciências versus uma "certa paralisação do campo artístico" (1968a: 309), pois à arte "é imposto um limite não superável e que provavelmente foi alcançado há muito tempo, impossível de ser estendido" (1968a: 309). A partir desta diferenciação do campo artístico reavaliamos, através de publicações como as de Koethe (1999), Compagnon (1999), Werber (1992) e de Luhmann (1980, 1981 e 1984), os conceitos de autonomia ("arte pela arte"), do belo e do sublime como referências destacadas na discussão sobre o estado e as origens da arte moderna. 


\section{Autonomia, gosto e o sensus aestheticus communis}

A estética, como nova disciplina da filosofia, foi fundada em 1750 por Alexander Gottlieb Baumgarten. A essa diferenciação na filosofia corresponde uma redefinição das artes no mesmo período. A antiga diferença entre artes liberais (inclusive a ciência e o conhecimento em geral) e artes mecânicas (artesãos) começa a ser modificada. A pintura e a escultura, por exemplo, até a Renascença consideradas artes mecânicas, são incluídas nas artes liberais, não por razões estéticas, mas por causa de sua qualidade quase científica e matemática, razão pela qual "Leonardo da Vinci tentava definir a pintura como ciência e enfatizava sua relação próxima à matemática" (Thomson 1969: 252).

No final do século XVII realizou-se, no contexto da ascensão social e econômica da burguesia, uma transformação significativa das categorias das artes. A burguesia se revoltou contra a discriminação social dos trabalhos artesanais e manuais frente às atividades livres. $\mathrm{O}$ choque da técnica proto-industrial com a velha divisão e hierarquização é documentado no artigo sobre arte da enciclopédia de Diderot:

Ao examinar os produtos das artes chegou-se à conclusão de que uns eram mais resultado da obra da mente que da mão e outros mais o resultado da mão que da mente. Em parte, isso explica a preferência que se deu a certas artes frente a outras e a divisão das artes em artes livres e artes mecânicas. Essa diferenciação causou um efeito negativo, pois diminuiu o prestígio de pessoas muito respeitáveis e úteis [...] (Diderot 1969: 184).

Nota-se aqui a substituição do princípio estratificatório pelo princípio funcional, pois as artes mecânicas realizam agora uma função social relevante e sua relação com outras artes não pode mais ser definida através de um ranking. Após diversos ajustes, incluindo a renomeação de artes liberais como belas-artes no século XVIII, estabeleceu-se, por volta de 1800, a categoria arte, no singular, abrangendo as áreas de música, literatura e artes plásticas.

Kant, ao "entender o belo como prazer desinteressado e como uma 'adequabilidade a fins sem finalidade’ (Zweckmässigkeit obne Zweck: ge- 
ralmente mal traduzida por finalidade sem fim)" (Котне 1999: 79), reflete este processo, distanciando a arte de critérios alheios e atribuindo a ela uma competência própria. De forma exemplar, Bubner destaca a importância de Kant quanto à elaboração de uma primeira comunicação estética autônoma capaz de fazer jus à produção artística moderna.

Especificamente a arte moderna revelou que a estética filosófica precisa recorrer à própria experiência estética caso ela não queira se desligar das manifestações nas quais a arte se apresenta. Se faz parte do caráter da arte moderna o novo de seus avanços, a conquista de terrenos desconhecidos, a negação radical de formas estabelecidas, a autodestruição, a tendência para efeitos de choque, a experiência estética torna-se a única fonte confiável de informação. A atualidade da estética kantiana consiste no fato de que ela apresentou uma análise insuperada, na sua sutilidade e intensidade, dessa experiência, sem se submeter a nenhuma heteronomia (BUBNER 1973: 72).

A diferença comunicativa entre arte, moral e ciência é tornada nítida por Kant: "Nenhum conceito do bem pode determinar o juízo do gosto" (KANT 1974: 136). Discursos científicos ou morais ferem por princípio a esfera específica do belo e do feio. Somente o sentimento de prazer ou desprazer do sujeito fundamenta julgamentos de gosto adequados à arte. Esse sentimento é evocado pela "forma" de um objeto. "Apenas aquilo que agrada através da sua forma, que possui uma forma bela, causa aquele prazer da harmonia da capacidade de conhecimento no estado de um jogo livre" (KANT 1974: 132), que legitima o julgamento de uma obra de arte. O sentimento do belo é um julgamento reflexivo, singular, que, mesmo assim, reivindica o universal.

Com Kant termina a ontologização do belo. Conforme o filósofo, "a beleza por si, sem relação com o sentimento do sujeito, é nada" (KANT 1974: 133). Não é o objeto que é belo, mas somos nós que chamamos um objeto de belo. Karl Philip Moritz já antecipou Kant quando enfatizou, em 1786, a dependência do belo em relação ao observador do substrato material: "Nós podemos muito bem existir sem contemplar belas obras de arte, mas essas, como tais, não existem sem a nossa contemplação" (1962: 4). Há belas obras, como artefatos, mesmo sem observadores, mas obras artísti- 
cas, como tais, se tornam arte somente através da sua recepção. É na comunicação que elas alcançam sua verdadeira existência. Em Crítica da Faculdade do Juíro, Kant também parte da comunicabilidade de um sentimento subjetivo ao invés da ontologia. Disso resulta que "nós procuramos no julgamento do belo, a priori, dentro de nós mesmos, a medida desse, e a própria faculdade do juízo estético é lei no julgamento" (1974: 29).

Com isso, o que é ou não é belo, quem não possui gosto ou o possui, não é mais resultado da "interação nas camadas dominantes" (LuHMANN, 1980b: 72), mas é analisado em uma investigação sobre julgamentos compartilháveis e comunicáveis. Kant realiza semanticamente a mudança de estratificação para função: de um gosto marcado pela convenção cortês nas capitais e residências para a consolidação do juízo (Urteilskraft) como capacidade geral que substitui a disputa dos juízes da arte sobre a classificação indefinida entre sentimento (je ne sais quoi) e razão (regras poéticas), em favor de uma comunicação estética autônoma que, ao invés de restringir as participações, defende uma inclusão geral.

Essa comunicação, apesar de partir do indivíduo, assegura sua generalidade através do sensus aestheticus communis, originando-se da identidade da faculdade humana. A pretensão universal do julgamento está abstratamente fundamentada, segundo Kant, em seu caráter desinteressado e não pervertido por nenhum interesse pessoal. Compagnon critica essa concepção como precária.

Kant, após estabelecer a subjetividade do julgamento estético, tenta escapar da conseqüência inelutável da relatividade desse julgamento; esforça-se desesperadamente por preservar um sensus communis dos valores, uma hierarquia estética legítima. (COMPAGNON 1999: 233).

Nós não vemos aqui um nivelamento objetivado que possa abolir diferenças de sensibilidade no julgamento estético, mas entendemos esse senso como garantia transcendental de consenso, um potencial existente mesmo quando de fato há julgamentos divergentes. Pode-se ver sua insistência na validade geral do julgamento do belo e, com isso, a negação do dissenso como tentativa de assegurar às comunicações estéticas uma complexidade própria que se diferencia do conhecimento científico sem ser um campo de opiniões particulares. 
Observamos a mesma tentativa de interligar individualidade e comunicabilidade na concepção kantiana do gênio. Nela, é preciso distinguir entre os falsos gênios, chamados por Kant de "macacos gênios" (KANT 1968b: 226), que prejudicariam o progresso da ciência e da moral com seus discursos pretensiosos e pobres, e aqueles aos quais a natureza concedeu um talento único. Assim, a obra do artista genial não é o resultado de uma arbitrariedade pura, nem o resultado previsível de regras produtivas. "É a natureza que precisa dar, no sujeito, a regra à arte, quer dizer, a bela arte é apenas possível como produto do gênio" (KANT 1968a: 307). Kant define o talento natural da genialidade nos seguintes itens: primeiro, a característica da originalidade, seu desvio da norma e sua orientação inovadora; segundo, a característica do exemplar, pois existe também "bobagem original" (KANT 1968a: 308); terceiro, a inconsciência do gênio quanto ao seu fazer. O exemplar consiste no fato de que a obra possui uma obrigatoriedade em relação à sua compreensão e interpretação. Há nela uma regra singular que normatiza sua avaliação e que somente é válida para essa obra. O gênio não sabe "como as idéias se formam nele e não tem poder de planejar ou compartilhar com outros sua produtividade" (KANT 1968a: 308). Por isso, a quarta característica: há apenas necessidade de gênio na arte, não na ciência, pois essa última se constitui num processo racional e recapitulável. "Nas ciências, há apenas uma diferença de grau entre o inventor mais destacado e um aprendiz enquanto existe uma diferença específica entre ele e aquele dotado pela natureza para a bela arte" (KANT 1968a: 309). Ao introduzir a natureza como legitimação do gênio para destecnicizar a arte, Kant concede à ciência uma dinâmica própria inexistente na arte, "à qual é imposto um limite não superável e que provavelmente foi alcançado há muito tempo, impossível de ser estendido” (KANT 1968a: 309), frase já citada na introdução. A virada para uma reflexão sobre a temporalidade da arte moderna na busca de rupturas e sua inclinação para inovações acontecerá de maneira fulminante na poética romântica.

A faculdade específica do gênio consiste em apresentar idéias estéticas. "Entendo uma idéia estética como aquela forma de imaginação que faz pensar muito sem que um certo pensamento ou conceito possa lhe ser adequado e que, conseqüentemente, nenhuma língua pode alcançar por completo para torná-la compreensível" (KANT 1968a: 316). O artista gênio produz então um excesso sensual da imaginação que resiste ao disciplinamento conceitual 
e que exige um direito próprio. Os conceitos abstratos da razão estão sendo suspensos e perdem seu caráter inequívoco, enquanto o singular e específico experimenta uma valorização. A idéia estética "permite associar a um conceito muitos elementos inomináveis cujo sentimento vivifica a faculdade de conhecimento e interliga a língua, como mera letra, ao espírito" (KANT 1968a: 316). A imaginação do gênio, libertada das coações discursivas da razão é, então, o princípio constitutivo da obra de arte, irredutível ao conhecimento científico e garantia da autonomia artística. Apesar de a fantasia do artista se retirar da reconstrução conceitual, ela não é sem limites, pois precisa de um disciplinamento pelo gosto para que seu "vôo livre" respeite as condições gerais do conhecimento humano e corresponda, de forma informal, às leis da razão. "O gosto é a disciplina do gênio e lhe corta as asas [...] ao mesmo tempo lhe oferece uma orientação [...]" (KANT 1968a: 319).

Vêem-se as similaridades entre artista e observador do belo. O gênio é capaz de iniciar o "jogo lúdico" e colocar, de forma produtiva, sua imaginação na obra, e essa, depois, estimula uma reação correspondente no receptor. Mas a visão da idéia estética por si só precisa, para ser comunicável, de habilidades técnicas. "O gênio pode apenas oferecer uma matéria rica à bela arte; o processamento dessa e a forma exigem um talento formado pela escola para fazer um uso que consegue ultrapassar a faculdade do juízo" (KANT 1968a: 310). Essa concepção permite entender melhor um tema freqüente do romantismo, o artista sem obra, no qual o gênio, incapaz de transformar suas visões em formas materiais, insiste mesmo assim em ser artista, como no caso de Werther "Estou tão feliz [...]. Neste momento, não poderia desenhar uma linha sequer, e, no entanto, nunca fui um pintor mais abençoado do que agora" (GOETHE 1998a: 9).

Com referência às diferentes formas artísticas, Kant atribui à poesia um lugar destacado. $\mathrm{Na}$ comunicação com o texto poético, experimentamos, desprendidos dos sentidos e do intelecto discursivo, uma plenitude do mundo impossível de alcançar na vida empírica. O desinteresse da posição estética se diferencia, por exemplo, do interesse moral pela distância em relação a seu objeto que a motivou. Enquanto a complacência moral objetiva a existência de uma ação e o agradável apenas estimula os sentidos, a experiência estética neutraliza, conforme Kant, os dois pólos, os sentidos e a razão, e consegue transformá-los num estado de "jogo lúdico livre” em 
que a razão retira dos sentidos seu rigoroso caráter imediato (Unmittelbarkeit), enquanto os sentidos retiram da razão sua obrigatoriedade de atuar em conceitos (Begriffszwang). Acontece, então, na experiência estética um balanceamento (Ausgleich) de sentido e razão. O julgamento do belo inicia o mecanismo geral do conhecimento de conceber algo singular sob um conceito geral sem que se fixe o específico num conceito final. Assim, o julgar estético pode ser considerado como parte das faculdades de conhecimento geral na forma de um sensus aestheticus communis, que tem como conseqüência a sua "comunicabilidade geral" (KANT 1974: 158). Kant parte da faculdade de cada pessoa de julgar a arte e o belo. Somente a disposição das capacidades de conhecimento é decisiva para proferir “julgamentos aceitáveis sobre objetos que então são considerados belos ou feios" (KANT 1974: 124). Julgamentos de gosto não são mais legitimados através de convenções diferenciadas hierarquicamente, mas se baseiam num fenômeno humano geral, o conjunto das faculdades de conhecimento.

\section{O ético e o estético}

Não concordamos com Kothe quando este afirma que, em Kant, "O belo, o correto e o verdadeiro estão conectados entre si, de um modo tal que nenhum pode ser pensado sem a unidade que ele constitui com os demais" (Kотне 1999: 80). Na nossa visão, Kant diferencia claramente os referidos campos.

Primeiro, ele reflete sobre a comunicação estética como sistema próprio para depois observá-la como ambiente de outros sistemas, como o ético. A tematização moral do belo já pressupõe sua autonomia. "Mostramos detalhadamente acima que o julgamento do gosto, através do qual se declara algo como belo, não precisa ter um interesse como justificativa. Mas disso não resulta a conseqüência de que, depois de ser realizado como julgamento estético puro, não possa ser ligado a um interesse" (KANT 1968a: 296). A autonomia do belo e da arte não exige a renúncia a qualquer comunicação não-estética, mas Kant admite aqui observações referentes ao belo a partir de outros campos que trabalham com outras diferenças. Para a moral, o belo pode ser considerado bom ou mal, assim como para a estética, o mal pode ter qualidades belas. 
Mas o belo como instrumento do bem é impuro. O que serve para fins alheios como "tratado moral e sermão" não pertence à arte. Mesmo "vestidos em forma de bela arte, não os chamamos obras artísticas" (KANT 1968a: 249). Fins externos e arte se excluem. A arte precisa, primeiramente, exercer sua própria função. Kant insiste nas condições específicas de uma comunicação estética adequada sem excluir a possibilidade de se cristalizar outros interesses ao redor do objeto da comunicação. O que é belo também pode ser útil. Assim, pode-se "colocar o motivo para uma finalidade naquilo que já agradou em si, sem consideração para qualquer finalidade" (KANT 1968a: 229). Finalidade significa, neste sentido, fins externos, para além do sistema da arte. A comunicação estética não se pode deixar influenciar, no processo do seu juízo autônomo, por esses fins externos à arte, se ela não quiser recair na posição antiga de uma condução externa.

Mas Kant também constata que a arte ganha em importância na referência de sistemas coexistentes, fato chamado de realizações secundárias (Leistungen) por Luhmann na sua teoria dos sistemas. Fala-se de realizações secundárias quando um sistema social provoca seleções num sistema social coexistente. A arte, por exemplo, é utilizada economicamente pela moda; ou produz comunicações, que contribuem para convicções religiosas, políticas ou para o campo da educação. O critério da realização secundária (Leistung) é "sua utilidade: o fato da sua inclusão e seu processamento em outros sistemas parciais" (LUHMANn 1981: 261).

A arte pode, então, se tornar instrutiva no âmbito da educação. Mas a educação não é sua primeira função. A arte não se torna arte pelo fato de produzir rendimentos para sistemas parciais. Voltando para Kant, a arte promove para a sociedade "humanidade" e "sociabilidade", sem que isso possa ser confundido com a função da arte. Da mesma maneira, ela produz rendimentos para a ciência e a moral. Esses não são os objetivos principais da arte, mas apenas efeitos "colaterais", que somente na perspectiva dos respectivos sistemas são estilizados como objetivos.

Com referência ao último ponto de nossas observações sobre a ética de Kant, quanto à relação entre o belo e o ético, Kothe afirma que o filósofo entende o sublime como símbolo do eticamente correto, resultando numa relação em que "o ético e o artístico se afirmam" (1999: 80). Mas é preciso ressaltar que Kant não entende esse simbólico no sentido de que uma boa ação, no âmbito da arte, poderia representar um símbolo do bem 
absoluto da razão. Antes de tudo, compreende o símbolo de maneira metafórica, ou seja, o belo é uma metáfora do bem, como mostra no seguinte exemplo:

Um estado monárquico é representado por um corpo animado quando é governado por leis internas do povo, mas por uma mera máquina quando é dominado por uma única vontade; nos dois casos essa representação é simbólica. Pois, apesar de não haver similaridades entre um Estado despótico e uma máquina, essas existem entre as regras através das quais se reflete sobre ambos e sua causalidade (KANT 1968a: 352).

Igualmente à máquina e ao governo despótico, não há nada em comum entre o belo e o bem. Eles não formam uma unidade, mas apenas são comparáveis sob um ângulo específico. Conforme Kant, esse consiste no fato de que as características estruturais da posição estética também valem para a posição moral relativa ao bem. Como símbolo, o belo não fornece ou simboliza um conteúdo direto do bem ético, mas apenas remete a suas condições e especificidades constitutivas. Assim, confirma-se a separação entre ética e estética sem abandonar o princípio básico estruturador em comum, uma concepção parecida com a da teoria dos sistemas, segundo a qual cada sistema, da mesma maneira, se forma e se reproduz na base dos mesmos processos estruturais.

Com isso, Kant coloca a auto-referência contra a heteronomia. Medidas externas de julgar, tanto como aclamações funcionais alheias, são rejeitadas como inadequadas. A "bela arte" significa uma "arte livre", soberana no seu território, sem que isso signifique arbitrariedade. "Cada arte pressupõe regras e é o gênio através do qual a natureza as fornece" (KANT 1974: 242).

A característica do gênio é sua "originalidade" que produz inovações. Mas, ao mesmo tempo, o gênio precisa ser exemplar. A medida para o juízo da arte seria, então, a própria arte. Para evitar formas tautológicas de auto-referência, Kant usa o conceito do gosto, que disciplina o gênio. A originalidade genial produz um "material rico", mas a arbitrariedade na formação é limitada pelo "gosto que possa perdurar frente ao juízo" (KANT 1974: 245). 


\section{O belo e o sublime}

Ainda é necessário responder à pergunta do porquê de Kant definir a fonte das formas artísticas no exterior do campo da comunicação artística. Por que "a própria bela arte não pode pensar a regra conforme a qual ela fabrica seu produto?" (KANT 1974: 242).

A teoria dos sistemas concebe a arte sob a diretriz da autopoiésis. $\mathrm{Na}$ arte como sistema comunicativo, as unidades, das quais se compõe o sistema, são produzidas pelo próprio sistema num processo permanente de comunicações específicas. Este processo de auto-reprodução está sujeito a condições internas de condução, por exemplo, programações historicamente variáveis do código. O sistema é fechado operacionalmente, mas, ao mesmo tempo, aberto a irritações e estímulos do ambiente. Ao situar o gênio como motor quase natural da arte no exterior do sistema da arte, Kant externaliza uma parte bastante importante da arte e a entrega à natureza. "Genialidade é um ingenium de nascimento" (1974: 242) e não uma propriedade produzida e controlada pelo sistema da arte.

Essa visão tem sua origem na concepção, dominante na virada do século XVIII, de que a sociedade é uma totalidade que consiste de partes, os indivíduos (LuHMann 1984: 21-23). Esferas sociais não podem ser pensadas sem representantes individuais. Kant segue esse dispositivo e transforma a totalidade da arte no plural de gênios originais, garantindo um campo destacado com seqüências comunicativas conectáveis através do elemento "gosto". Esse não é um produto da natureza, mas possui no juízo um fundamento transcendental. É verdade que "a bela arte somente é possível como produto do gênio, que, como natureza, dá as regras" (KANT 1974: 242). Mas ao colocar o gênio no exterior dos sistemas sociais, Kant precisa delimitar a projeção de sua função. O gênio apenas gera "a matéria para produtos da bela arte" (KANT 1974: 245), enquanto as decisões referentes à forma são restritas ao juízo via estudo, aprendizagem e reflexão consciente dentro do âmbito da sociedade.

Partimos da definição de Kant do belo "como prazer desinteressado e como uma adequabilidade a fins sem finalidade" (Kотне 1999: 79). Concebemos o belo como fenômeno cuja organização formal apresenta uma adequabilidade em relação ao nosso juízo de conhecimento que possibilita uma comtemplação prazerosa. No lado oposto desse, Kant coloca o subli- 
me, o "prazer negativo" (KANT 1968a: 245), uma experiência explicitamente delimitada para o campo de fenômenos naturais. Esses são chamados de sublime quando superam nossa imaginação e com isso causam uma sensação ambivalente de desprazer.

O oceano imenso, revoltado por tempestades, não pode ser chamado de sublime. Seu aspecto é terrível e é preciso ter uma mente cheia de idéias variadas para poder, nessas circunstâncias, gerar um sentimento que seja, ele próprio, sublime ao estimular a mente a abandonar a sensualidade e se ocupar com idéias que contenham uma adequabilidade mais elevada (KANT 1968a: 245).

O mar tempestuoso ameaçador alarma nossos sentidos e os sobrecarrega, delimitando nossa faculdade de percepção. Mas esse colapso de nossa natureza sensual contém uma adequabilidade que estimula o prazer, pois possibilita comceber nossos potenciais sobre-sensuais: a competência para a razão que vai além do terrível dos elementos. Enquanto no belo experimentamos a harmonia dos sentidos com nossa faculdade de razão, no sublime elevamo-nos (o sublime, das Erbabene, origina-se do verbo erheben ou elevar em português) para além dos limites da natureza sensual e nos experimentamos como seres da razão.

O belo precisa da sensualidade, de forma positiva, como contrapeso à discursividade do intelecto e sua obrigatoriedade de atuar com conceitos. O sublime precisa da sensualidade de forma negativa para encenar o fracasso dessa como vitória da razão sobre todas as limitações sensuais do sujeito. Podemos conceber o oceano como espaço de tal grandeza, em ambos os sentidos, que se torna inexperimentável na sua totalidade. Conforme Kant, o sujeito vivencia esse momento de falha da faculdade imaginativa também como apelo à sua razão e à faculdade dessa de pensar a totalidade, como momento sublime. $\mathrm{O}$ fracasso dos sentidos torna-se o prazer da razão, mas sob a condição de que a força da natureza não nos ameace de forma direta e de que possamos experimentá-la a partir de uma distância segura. "Sua contemplação torna-se tão mais atrativa quão mais terrível ela se apresente conquanto estejamos em lugar seguro" (KANT 1968a: 261). Kant relaciona, então, sua concepção do sublime aos fenômenos da natureza que sobrecarregam nossos sentidos, mas transformam essa dissonân- 
cia de sentidos e síntese conceitual em uma presença não representável, apenas emergente nas rupturas, da razão e suas "idéias de totalidade, liberdade e imortalidade da alma” (KANT 1968a: 264).

Aproximando o sublime da arte, podemos afirmar que a arte obtém sua significação não da presença do apresentado, mas da ausência, do nãodito que remete infinitamente a algo além de qualquer conceituação fixa.

Talvez não exista trecho mais sublime no livro sagrado judaico que o mandamento: não farás uma imagem e nem uma alegoria daquilo que é no céu e na terra. Esse mandamento sozinho é capaz de explicar o entusiasmo que o povo judeu sentiu [...] por sua religião [...] (KANT 1968a: 274).

O absoluto é apenas apresentável como falta e sua ausência é fonte inesgotável para a reflexão. Para Kant, as falhas de uma arte sublime, que encena nas lacunas dos signos o traço daquilo indizível a ela, remetem a um espaço onde essas desapareciam à luz da razão. Essa necessita dos sentidos para, no momento sublime, ultrapassar seus limites de maneira prazerosa. A teoria pós-moderna, pelo menos na avaliação de Lyotard, retoma enfaticamente a idéia do inapresentável como elemento constitutivo:

O pós-moderno é aquilo que remete, na sua apresentação, a um nãoapresentável [...] que inicia uma procura de novas apresentações [...] para afiar a sensibilidade para o fato de que existe o inapresentável. [...] Dever-se-ia finalmente chegar à conclusão de que não cabe a nós entregar a realidade, mas achar alusões a um pensável que não possa ser apresentado (1985: 47).

\section{Arte pela arte}

Enfatizamos em Kant o fato de que ele formulou explicitamente a auto-referência da arte. A fórmula para essa nova auto-referencialidade de uma arte, que rejeita programaticamente todas as exigências externas como utilidade ou elevação moral, chama-se, na estética dos últimos cento e cinqüenta anos, l'art pour l'art, atribuída normalmente ao esteticismo francês da metade do século XIX. Anke Wiegand, por exemplo, escreve: 
Essa concepção foi divulgada por Cousin. Seu tratado Le V rai, le Beau et le Bien baseou-se na estética alemã . Também foi Cousin que cunhou a fórmula "l'art pour l'art": "Il faut comprendre et aimer la morale pour la morale, la religion pour la religion, l'art pour l'art" (apud WiEgand 1967: 100).

Portanto, conforme Werber (1992), há indícios de que essa expressão famosa para a autonomia da arte se deva diretamente a Immanuel Kant. Um jovem estudante, Henry Crabb Robinson, freqüentava em Jena, logo depois da morte de Kant, as aulas de Schelling sobre a filosofia kantiana. No seu Letters on German Literature, escrito periodicamente, encontra-se um ensaio sobre Kant's analysis of beauty, com as seguintes anotações: "the beautiful has no object or end beyond itself, it pleases because it is, in itself alone" (apud Werber 1992: 47). O belo não possui fins externos, o juízo estético olha, portanto, sem interesse moral ou materialista para seu objeto. O ensaio de Robinson tem conseqüências. No dia 11 de fevereiro de 1804, o francês Benjamin Constant, viajando, o lê e anota no seu diário:

Almocei com Robinson, um aluno de Schelling. Seu trabalho sobre a estética de Kant. Idéias muito inteligentes. Arte pela arte, sem interesse, qualquer interesse é contra a natureza da arte. Mesmo assim a arte chega a um tal apesar de não o ter possuído antes (1970: 71).

No original, em francês, está escrito L'art pour l'art, et sans but, dando origem a essa expressão que surge, assim, diretamente da recepção da filosofia de Kant. Para Constant, essa teoria da autonomia da arte parece ser uma realização especificamente alemã, totalmente em contraposição à literatura francesa:

A literatura francesa possui, ao lado da beleza poética, sempre um interesse, seja ele a moral, a utilidade, experiência de vida ou persiflage.[...] Por isso, ela serve sempre como pretexto ou meio. Em nenhum lugar encontra-se tudo aquilo que é essencial à poética alemã e me parece ser a essência verdadeira da poesia.[...] Disso resulta que pessoas acostumadas a procurar na literatura alguma outra coisa que a poesia não a acharão na literatura alemã. É como um matemático que fala da 
Iphigenea: $\mathrm{O}$ que isso comprova? Os estrangeiros comentam a literatura alemã: aonde isso quer chegar? (CONSTANT 1970: 108).

Para o francês Constant, a literatura alemã se apresenta como novidade da época, uma literatura sem interesses / fins externos e auto-suficiente. Portanto, Constant reflete sobre o fato de que a arte pudesse realizar interesses sem que isso fosse seu atributo explícito. Germaine de Stael, uma amiga próxima de Constant, retoma esse pensamento em 1814 e o transmite para um público maior:

Ao separar o belo do útil, Kant comprova que não está na natureza das belas-artes fornecer regulamentos. Sem dúvida, tudo que é belo precisa evocar sentimentos generosos e esses sentimentos têm que estimular virtudes, mas no momento que se pretende apresentar um regulamento moral, a impressão livre das obras primas da arte é destruída, pois o interesse, seja o que for, não pode ser pensado sem limitar e coagir a imaginação (1985: 578).

Objetivos morais são apenas interesses secundários com os quais a literatura satisfaz certas exigências. Quase na mesma época, Goethe formulou o mesmo pensamento da seguinte forma: "Uma boa obra de arte pode e vai ter conseqüências morais, mas exigir fins morais do artista significa destruir seu oficio" (GoETHE 1975b: 600).

\section{Referências bibliográficas}

BUBNER, Rüdiger. „Über einige Bedingungen gegenwärtiger Ästhetik.“ In: neue hefte für Philosophie. Göttingen, Vandenhoeck \& Ruprecht 1973. V. 5.

Compagnon, Antoine. O demônio da teoria. Belo Horizonte, Editora UFMG 1999.

Constant De Rebeque, Benjamin. Tagebuch II. In: B. C. D. R. Werke in vier Bänden. Berlin, Propyläen-Verlag 1970. V. 1.

Diderot, Denis. Enzylklopädie. München, Deutscher Taschenbuch Verlag 1969. 
Duarte, Rodrigo (Org.). Belo, Sublime e Kant. Belo Horizonte, Editora da UFMG 1998.

Gozthe, Johann Wolfgang von. Os Sofrimentos do Jovem Werther. São Paulo, Martins Fontes 1998.

Goethe, Johnann Wolfgang von. Dichtung und Wahrheit. Frankfurt/M, Insel Verlag 1975.

Kant, Immanuel. Akademieausgabe. Berlin, Brandenburgische Akademie der Wissenschaften 1968a. V. 5.

Kant, Immanuel. Akademieausgabe. Berlin, Brandenburgische Akademie der Wissenschaften 1968b. V. 7.

KANT, Immanuel. Kritike der Urteilskraft. Frankfurt/M., Suhrkamp 1974.

Kothe, Flavio R. “Da recepção como reação.” In: Brito, Célia Maria Coêlho (Org.): Moara n. 11, p. 65-89, jul./dez. 1999.

Lima, Luiz Costa. Mimesis. Rio de Janeiro, Ensaio 2000.

LuHmann, Niklas. Gesellschaftsstruktur und Semantik. Frankfurt/M., Suhrkamp 1980. v. 2.

Luhmann, Niklas. Soziologische Aufklärung. Opladen, Westdeutscher Verlag 1981. V. 3.

Luhmann, Niklas. Soziale Systeme. Frankfurt/M., Suhrkamp 1984.

Lyotard, Jean-François. Das Interesse am Erhabenen. In: Pries, Christine (Org.): Das Erbabene: zwischen Grenzerfahrung und Größenwahn. Weinheim, VCH, Acta Humaniora 1989.

Moritz, Karl Philipp. Schriften zur Ästhetik und Poetik. Tübingen, Niemeyer 1962.

Novalis. Werke und Briefe. München, Winkler 1962.

STAËL, Anne Louise Germaine de. Über Deutschland. Frankfurt/M., Insel Verlag 1985.

Thomson, Samuel Harrison. Das Zeitalter der Renaissance. München, Deutscher Taschenbuch Verlag 1969.

WERBER, Niels. Literatur als System. Opladen, Westdeutscher Verlag 1992.

Wiegand, Anke. Die Schönheit und das Böse. München, Pustet 1967. 